\title{
Piperlongumine selectively kills hepatocellular carcinoma cells and preferentially inhibits their invasion via ROS-ER-MAPKs- CHOP
}

\author{
Yong Chen ${ }^{1}$, Ju Mei Liu ${ }^{1}$, Xin Xin Xiong ${ }^{1}$, Xin Yao Qiu ${ }^{1}$, Feng Pan ${ }^{2}$, Di Liu ${ }^{2}$, Shu Jue \\ Lan $^{3}$, Si Jin ${ }^{4}$, Shang Bin Y $\mathbf{u}^{1}$ and Xiao Qian Chen ${ }^{1}$ \\ ${ }^{1}$ Department of Pathophysiology, School of Basic Medicine, Tongji Medical College, Institute of Brain Research, Key Laboratory \\ of Neurological Diseases, Ministry of Education, Hubei Provincial Key Laboratory of Neurological Diseases, Huazhong \\ University of Science and Technology, Wuhan, China \\ 2 Department of Urology, Union Hospital, Huazhong University of Science and Technology, Wuhan, China \\ 3 Institute of Biochemistry and Cell Biology, Shanghai Institutes for Biological Sciences, Chinese Academy of Sciences, \\ Shanghai, China \\ ${ }^{4}$ Department of Pharmacology, School of Basic Medicine, Huazhong University of Science and Technology, Wuhan, China \\ Correspondence to: Xiao Qian Chen, email: chenxq@mails.tjmu.edu.cn \\ Keywords: piperlongumine, hepatocellular carcinoma, oxidative stress, signaling pathway, chemotherapy \\ Received: December 21,2014 Accepted: January 21,2015 Published: January 31, 2015
}

This is an open-access article distributed under the terms of the Creative Commons Attribution License, which permits unrestricted use, distribution, and reproduction in any medium, provided the original author and source are credited.

\section{ABSTRACT}

Hepatocellular carcinomas (HCC) are highly malignant and aggressive tumors lack of effective therapeutic drugs. Piperlongumine (PL), a natural product isolated from longer pepper plants, is recently identified as a potent cytotoxic compound highly selective to cancer cells. Here, we reported that PL specifically suppressed HCC cell migration/invasion via endoplasmic reticulum (ER)-MAPKs-CHOP signaling pathway. PL selectively killed HCC cells but not normal hepatocytes with an $\mathrm{IC}_{50}$ of 10-20 $\mu \mathrm{M}$ while PL at much lower concentrations only suppressed HCC cell migration/ invasion. PL selectively elevated reactive oxygen species (ROS) in HCC cells, which activated or up-regulated downstream PERK/Ire 1a/Grp78, p38/JNK/Erk and CHOP subsequently. Administration of antioxidants completely abolished PL's effects on cell death and migration/invasion. However, pharmacological inhibition of ER stressresponses or MAPKs signaling pathways with corresponding specific inhibitors only reversed PL's effect on cell migration/invasion but not on cell death. Consistently, knocking-down of CHOP by RNA interference only reversed PL-suppressed HCC cell migration. Finally, PL significantly suppressed HCC development and activated the ER-MAPKs-CHOP signaling pathway in HCC xenografts in vivo. Taken together, PL selectively killed HCC cells and preferentially inhibited HCC cell migration/invasion via ROS-ER-MAPKs-CHOP axis, suggesting a novel therapeutic strategy for the highly malignant and aggressive HCC clinically.

\section{INTRODUCTION}

Liver cancers are highly malignant and aggressive tumors, making it the third leading cause of cancer death in the world [1]. Hepatocellular carcinoma (HCC) is the most common type of liver malignant tumors in adults. HCC usually occurs following a viral hepatitis infection (hepatitis B or C) or cirrhosis, in which complicated pathological processes induced by reactive oxygen species (ROS) are heavily involved [2]. ROS is considered as a two-edge sword in tumorigenesis and development. At the initial stage in HCC development, ROS or oxidative stress-responses mainly stimulate hepatocarcinogenesis or promote HCC development by activating pro-oncogenic gene activities or oncogenic signaling pathways such as mitogen-activated protein kinases (MAPKs) [3,4]. Along with the progression of HCC, ROS overproduction or longlasting oxidative stress-responses would tend to induce cell death or prevent cancer development in $\mathrm{HCC}[1,5]$. Therefore, modulating homeostasis of ROS or oxidative 
stress-responses has become an important therapeutic strategy for HCC $[5,6]$. Accumulative evidences support that oxidants have therapeutic effects in cancer treatment and the underlying mechanisms have been well studied $[5,7-11]$. It is well-known that ROS may alter various cellular signaling pathways profoundly depending on different cellular contexts and MAPKs (i.e., p38, JNK and Erk) are canonical ROS-responsive signaling pathways [812].Until now, the exact mechanisms of oxidative stressresponses in $\mathrm{HCC}$ development and treatment remain far from clear.

Piperlongumine (PL) is a biological active alkaloid existing largely in the long pepper (Piper longum L). PL has been traditionally used for treating gastrointestinal and respiratory diseases in Ayurvedic medicine [12]. Recently, PL was identified as a highly reliable and potent cytotoxic compound in killing cancer cells in screening study [13]. PL selectively kills cancer cells but leave normal cell intact as PL induces ROS accumulation only in cancer cells $[8,9,13]$. The PL induced selective accumulation of ROS in cancer cells represents a novel therapeutic strategy for cancers $[8,9,13,14]$. It is reported that PL might exert its cytotoxicity by activating p38 [9,11], JNK [9], Erk [15], Akt [16, 17], promoting protein glutathionylation [18], or suppressing NFאB activities [19] in different types of cancer cells. Further exploring the anticancer effects as well as its underlying mechanisms of PL is required for its clinical applications.

Endoplasmic reticulum (ER), a specific organelle for $\mathrm{Ca}^{2+}$ storage and proper protein folding/maturation, plays an important role in regulating ROS homeostasis and stress-responses [20]. Upon various pathological stimuli such as ROS or misfolded/unfolded proteins accumulation, ER homeostasis is disturbed and ER stress-responses are induced, leading to the activation of various downstream signaling pathways such as MAPKs and the induction of $\mathrm{C} / \mathrm{EBP}$ homologous protein (CHOP) $[21,22]$. Consequently, stressed cells may either restore its homeostasis or undergo programmed cell death such as apoptosis or autophage [23]. In various cancer cells including HCC cells, enhanced ER stress-responses have been well documented [24-26]. However, the effects of ER stress-responses (either promoting or inhibiting cancer development) vary depending on specific ER-downstream signaling pathways in specific cellular contexts [24, 27]. Considering the central role of ER in oxidative stressresponses in HCC, it is likely that ER-mediated stressresponses and its downstream signaling pathways might be heavily involved in PL's biological effects in HCC cells.

In the present study, we examined the anticancer effects of PL on HCC cells in vitro and in vivo, and further investigated the underlying mechanisms. Our data demonstrated that PL preferentially suppressed HCC cell migration and invasion via ER-MAPKs-CHOP depending on ROS.

\section{RESULTS}

\section{Piperlongumine selectively kills HCC cells but not normal hepatocytes}

We tested the cytotoxic effects of PL in human HCC cell lines to evaluate the therapeutic potential of PL for HCC. MTT assays demonstrated that $24 \mathrm{~h}$ of PL treatment induced a significant reduction in the cell viability of various HCC cells (HepG2, Huh7, LM3) in a concentration-dependent manner (PL 0, 5, 10, 15 and 20 $\mu \mathrm{M})$, but had little effect in that of primary rat hepatocytes and normal hepatic L-02 cells (Fig. 1A). The half maximal inhibitory concentration $\left(\mathrm{IC}_{50}\right)$ of PL in HCC cells was in the range of 10-20 $\mu \mathrm{M}$. Trypan blue assay showed that the rate of cell death was significantly increased in HepG2, Huh7 and LM3 cells at $24 \mathrm{~h}$ of PL treatment in a dosedependent manner (5-20 $\mu \mathrm{M})$ (Fig. 1B). Consistently, the rate of cell death as revealed by propidium iodide (PI) staining (PI-positive nuclei) was evidently increased in HepG2, LM3 (Fig. 1C) and Huh7 (Supplemental Figure 1) cells at $24 \mathrm{~h}$ of PL treatment in a dose-dependent manner (5-20 $\mu \mathrm{M})$. Further, the number of apoptotic cells as revealed by annexin V staining (annexin V-positive cells) was significantly increased at $24 \mathrm{~h}$ of PL-treatment (20 $\mu \mathrm{M})$ in HepG2 cells (Fig. 1D). In addition, flow cytometry (FCM) analysis showed that at $24 \mathrm{~h}$ of PL-treatment (20 $\mu \mathrm{M}$ ), the percent of sub-G1 cells (representing apoptotic cells) was increased in HepG2 cells while the ratio of $\mathrm{G} 1 /(\mathrm{S}+\mathrm{G} 2)$ was not altered (Fig. 1E). Taken together, PL selectively and effectively induced cell death including apoptosis in HCC cells.

\section{Piperlongumine preferentially suppresses HCC cell migration and invasion in vitro}

$\mathrm{HCC}$ are highly malignant tumors and cancer cell invasion or metastasis is the major cause of death. We examined the effects of PL on the ability of HCC cell migration and invasion in vitro. In the scratch-wound healing assay, cells along the wound-edge would migrate into the nude space after scratching and the scratch-wound would heal continuously (represented by the reduced scratch-wound sizes between the opposite scratching lines). In normal hepatic L-02 cells, PL treatment (within $10 \mu \mathrm{M}$ ) had no evident effect on the migration and the wound-healing speed was not altered within $48 \mathrm{~h}$ of PL treatment (Fig. 2A). In Huh7 (Fig. 2B) and HepG2 (Fig. 2C), however, PL prominently inhibited HCC cell migration and reduced wound-healing speed at 24 or $48 \mathrm{~h}$ of PL treatment in a dosage-dependent manner within 2.5$10 \mu \mathrm{M}$. Statistical analysis demonstrated that PL at lower concentrations $(2.5,5$ or $10 \mu \mathrm{M})$ significantly reduced wound sizes of Huh7 (Fig. 2B) or HepG2 (Fig. 2C) cells 

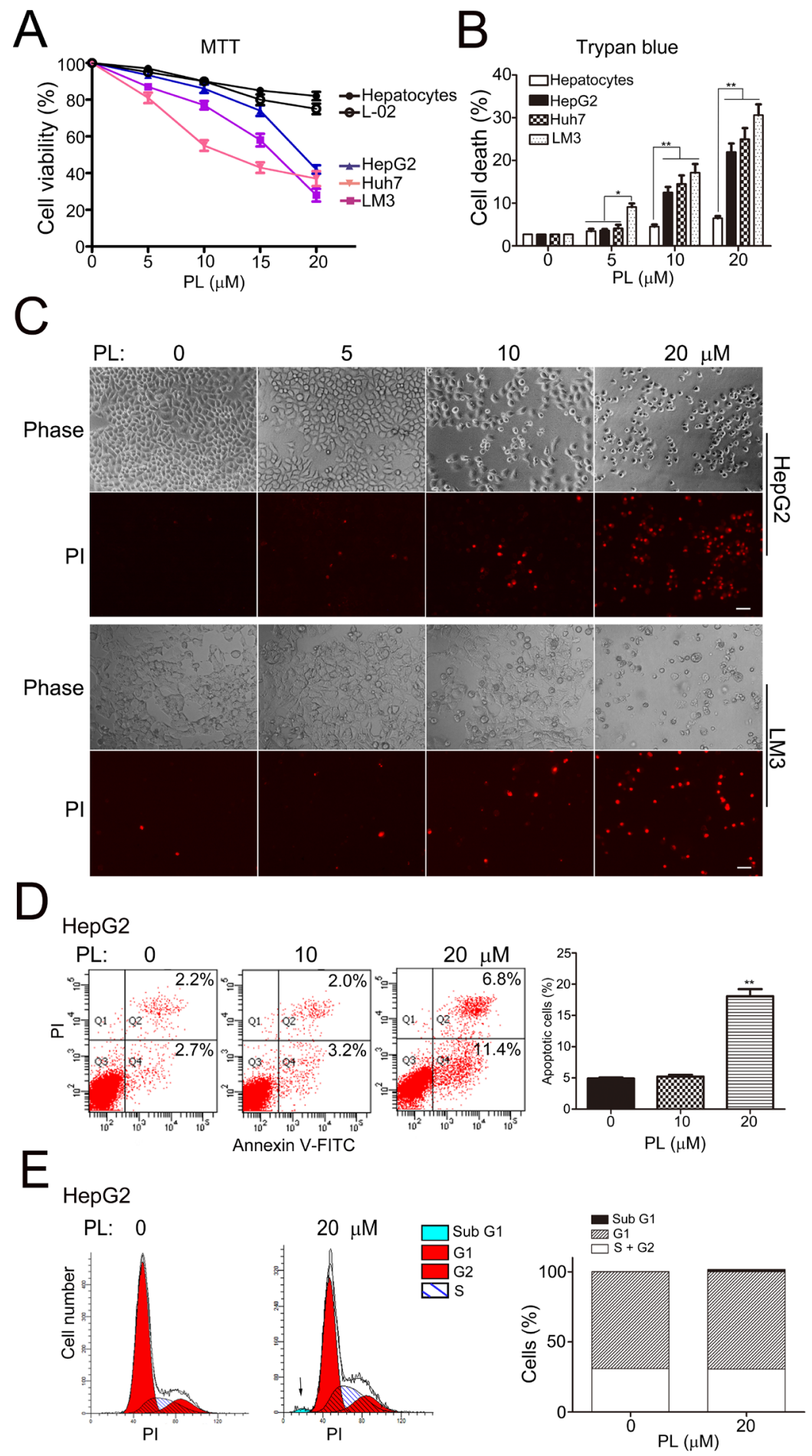

Figure 1: Piperlongumine selectively killed HCC cells but not normal hepatocytes. (A) Results of MTT assays showed the selective cytotoxicity of PL in HCC cells. HCC cell lines (HepG2, Huh7 and LM3), normal hepatic cell line (L-02) and primary rat hepatocytes were grown in 96-well plates for $24 \mathrm{~h}$ and subjected to PL treatment $(0,5,10,15$ or $20 \mu \mathrm{M})$ for $24 \mathrm{~h}$. Cell viability was measured by MTT assays $(n=3)$. All values represented mean \pm SEM of three independent experiments. (B) Statistical analysis of cell death in PL-treated HCC cells or primary hepatocytes as measured by trypan blue exclusion assays. ${ }^{*} P<0.05$, ${ }^{* *} P<0.01$ ( $\mathrm{n}=3$ ). (C) Representative micrographs of PI staining showed cell death in PL-treated HepG2 and LM3 cells. Bar, $20 \mu \mathrm{m}$. (D) Representative results of FCM analysis showed apoptosis in PL-treated HepG2 cell. HepG2 cells were treated with PL $(0,10$ or $20 \mu \mathrm{M})$ for 24 h. After annexin V-PI double staining, cells were subjected to FCM analysis. The percentages of cells in the Q2 together with Q4 quarters were calculated as apoptotic cells for statistical analysis in the right panel. $* * P<0.01 v s$. PL $0 \mu \mathrm{M}(\mathrm{n}=3)$. (E) Representative results of FCM analysis showed the effects of PL in cell cycle of HepG2 cells. HepG2 cells were treated with $20 \mu \mathrm{M}$ PL for $24 \mathrm{~h}$. After PI staining, cells were subjected for FCM analysis. The arrow indicated the sub-G1 population. 

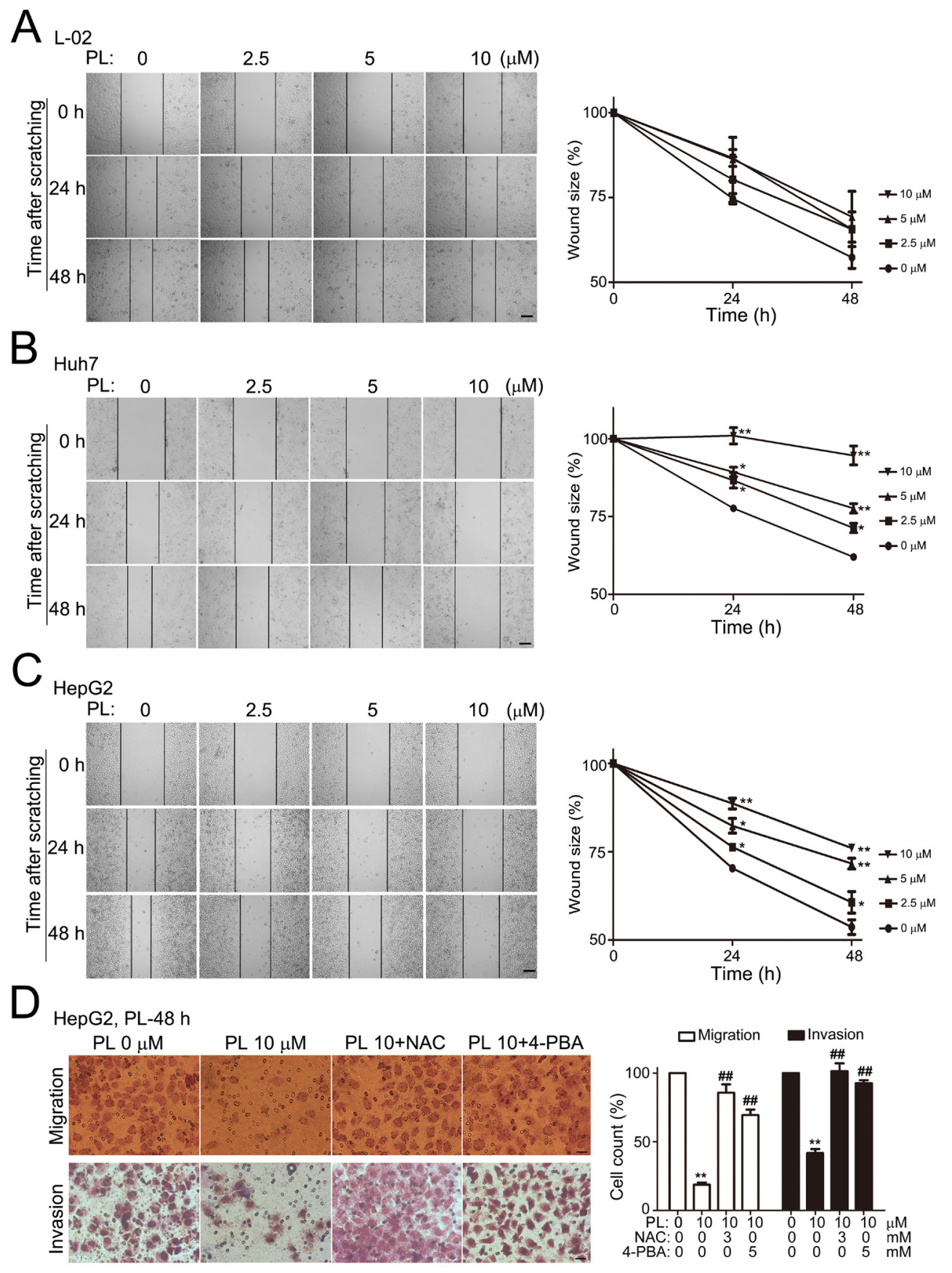

Figure 2: Piperlongumine selectively suppressed HCC cell migration or invasion in vitro. (A) Representative micrographs showed the effects of PL on L-02 cell migration after scratching. Confluent L-02 cells (normal hepatic cell line) in 35-mm culture dishes were subject to cell scratching with yellow pipettes. PL was added to the cultures with fresh culture media after brief culture rinsing. The scratch-wounds were photographed at various time points $(0,24$ and $48 \mathrm{~h})$ after cell scratching and the wound sizes were measured. Bar, $100 \mu \mathrm{m}$. Statistical analyses (right panel) demonstrated that PL with $10 \mu \mathrm{M}$ did not alter L-02 cell migration significantly (n=3). (B-C) Representative micrographs showed the effects of PL on Huh7 (B) and HepG2 (C) cell migration after cell scratching. Bar, $100 \mu \mathrm{m}$. Statistical analyses (right panel) demonstrated that PL with $2.5-10 \mu \mathrm{M}$ significantly altered Huh7 cell migration $48 \mathrm{~h}$ after cell scratching (n=3). ${ }^{*} P<0.05,{ }^{*} P<0.01$ vs. corresponding PL $0 \mu \mathrm{M}$ control (n=3). (D) Representative micrographs showed the effects of PL on HepG2 cell migration and invasion. HepG2 cells were seeded into the upper chamber of transwell apparatus without (upper panel) or with (lower panels) matrigel. Drugs (PL alone or together with NAC or 4-PBA) were added to the culture $24 \mathrm{~h}$ after cell seeding. Cell migration (upper panels) and invasion (lower panels) were induced by FBS-containing media in the lower chamber. Migrated and invaded cells in the lower surface of the filters were stained and microphotographed $24 \mathrm{~h}$ after serum induction. Bar, $20 \mu \mathrm{m}$. Statistical analyses (right panel) demonstrated migrated or invaded HepG2 cells were significantly reduced upon PL treatment while co-treatment of NAC or 4-PBA significantly reversed the effects of PL on cell migration or invasion. ${ }^{* *} P<0.01$ vs PL- $0 \mu \mathrm{M}$ and ${ }^{* \#} P<0.01$ vs corresponding PL $10 \mu \mathrm{M}$ control $(n=3)$. 
while cell death in HepG2 or Huh7 cells was not altered at $48 \mathrm{~h}$ of PL treatment at $10 \mu \mathrm{M}$ (Supplemental Fig. 2). Consistently, PL $(10 \mu \mathrm{M})$ prominently reduced HepG2 cell migration at $48 \mathrm{~h}$ of PL treatment in the transwell migration assays (left upper panels, Fig. 2D). Further, PL $(10 \mu \mathrm{M})$ significantly reduced invaded HepG 2 cells in the transwell invasion assay at $48 \mathrm{~h}$ after PL-treatment (left lower panels, Fig. 2D). Statistical analysis demonstrated that migrated or invaded HepG2 cells were significantly reduced at $48 \mathrm{~h}$ of PL treatment $(10 \mu \mathrm{M})$ (right panel, Fig. 2D). These evidences together demonstrated that PL preferentially suppressed HCC cell migration/invasion at lower PL concentrations.

\section{Piperlongumine induces ROS accumulation to exert its anti-cancer effects on HCC cells}

We then examined whether ROS accumulation is required for PL's anti-cancer effects in HCC cells as previous studies have shown that ROS is the major downstream player of PL's action in many types of cancer cells [13]. The fluorescent intensity of 2'-,7'-Dichlorofluorescin diacetate (DCFH-DA, a specific ROS indicator) in primary hepatocytes (Fig. 3A) or L-02 cells (Supplemental Fig. 3A) was not altered at $3 \mathrm{~h}$ of PL treatment (5, 10 and $20 \mu \mathrm{M})$. In HepG2 (Fig. 3B), Huh7 (Fig. 3C) and LM3 cells (Supplemental Fig. 3B), however, the fluorescent intensities of DCFH-DA were evidently enhanced at 1 or $3 \mathrm{~h}$ of PL treatment. Statistical analyses demonstrated that the intracellular ROS levels were significantly increased in HepG2 and Huh7 cells at $1 \mathrm{~h}$ of PL treatment (Fig. 3B and 3C). Pre-incubation of antioxidant N-acetyl-L-cysteine (NAC, $3 \mathrm{mM}$ ) completely abolished the effect of PL on ROS induction at $3 \mathrm{~h}$ of PL treatment in LM3 (Supplemental Fig. 3B) or HepG2 cells (Supplemental Fig. 3C). Consistently, intracellular glutathione (GSH) levels were significantly reduced in HepG2 or Huh7 cells at $1 \mathrm{~h}$ of PL treatment (Fig. 3D). Pre-treatment of NAC (3 mM) reversed PL's effect on GSH reduction (Fig. 3D). Pre-treatment of NAC or GSH completely reversed PL-induced cell death in Huh7 cells (Fig. 3E) and HepG2 cells (Fig. 3F) while delayed administration of antioxidants partially reversed PL-induced cell death in HCC cells at a time-dependent manner (Fig. 3E and 3F). In addition, administration of NAC completely reversed PL-suppressed cell migration in HepG2 cells after cell scratching (Fig. 3G). Consistently, NAC abolished the PL's suppression effect on cell migration in the transwell migration assay (left upper panels, Fig. 2D) and cell invasion in the transwell invasion assay (left lower panels, Fig. 2D).

\section{Piperlongumine induces ER stress-responses which preferentially suppresses HCC cell migration/invasion}

The downstream signaling pathways of ROS which is responsible for PL's anticancer effects remain elusive. We examined the role of ER stress-responses in PLtreated HCC cells as the ROS-ER axis plays a pivotal role in controlling ROS-mediated homeostasis and cellular effects [20]. Western blotting analysis showed that PKR-like ER kinase (PERK, a specific ER-stress responsive protein) was prominently activated in HepG2 (Fig. 4A) and LM3 (Fig. 4B) cells at various time points (e.g., $3 \mathrm{~h}$ as indicated by the red rectangular box) of PL treatment in a dosage-depedent manner $(0,5,10$ and 20 $\mu \mathrm{M})$. Fluorescent cytoimmunostaining assay also clearly showed that the level of phosphorylated PERK (p-PERK) was evidently increased in Huh7 (Fig. 4C) and HepG2 cells (Supplemental Fig. 4A) at various time points (3, 6 and $12 \mathrm{~h})$ of PL treatment $(20 \mu \mathrm{M})$. In addition, other ER-endocking proteins such as glucose-regulated protein 78 (Grp78, i.e., BiP) and inositol-requiring enzyme-1 $\alpha$ (Ire $1 \alpha$ ) were also clearly up-regulated at various time points of PL treatment in HepG2 (Fig. 4A) and LM3 (Fig. 4B) cells. Consistently, the downstream product of ER stress-response, CHOP, was also up-regulated evidently at various time points of PL treatment in HepG2 (Fig. 4A and Supplemental Fig. 4A), LM3 (Fig. 4B) and Huh7 cells (Fig. 4C). ER is a major organelle storing $\mathrm{Ca}^{2+}$ which is released into cytosol to activate downstream signaling pathways upon various stimuli including ROS [28]. In primary rat hepatocytes, the concentration of cytoplasmic free $\mathrm{Ca}^{2+}$ as measured by Fluro-3 AM (a specific fluorescent probe for free calcium) was not altered at $3 \mathrm{~h}$ of PL treatment $(0,5,10$ and $20 \mu \mathrm{M}$ ) (upper panels, Fig. 4D). In HepG2 (middle panels, Fig. 4D) and Huh7 (lower panels, Fig. 4D) cells, however, the concentration of cytoplasmic free $\mathrm{Ca}^{2+}$ was prominently increased at $3 \mathrm{~h}$ of PL treatment in a dose-dependent manner $(0-20 \mu \mathrm{M})$. These evidences together verified that PL induced ER stress-responses in HCC cells.

We then examined the roles of ER stress-responses in PL's anticancer effects in HCC cells by using specific ER stress-response inhibitor 4-phenylbutyric acid (4-PBA) $[29,30]$. MTT assay revealed that 4-PBA did not alter PLinduced cell viability reduction in HepG2 or LM3 cells (Supplemental Fig. 5A and 5C). Consistently, results of PI staining showed that 4-PBA did not alter PL-induced cell death in HepG2 cells (Supplemental Fig. 5B). However, 4-PBA completely abolished PL-suppressed cell migration in HepG2 (Fig. 4E) and Huh7 cells (Supplemental Fig. 6) at various time points after scratching. Consistently, 4-PBA significantly reversed PL-suppressed HepG2 cell migration in transwell migration assays and HepG2 cell invasion in the transwell invasion assays (Fig. 2D). The 
A

Primary rat hepatocytes, PL-3 h
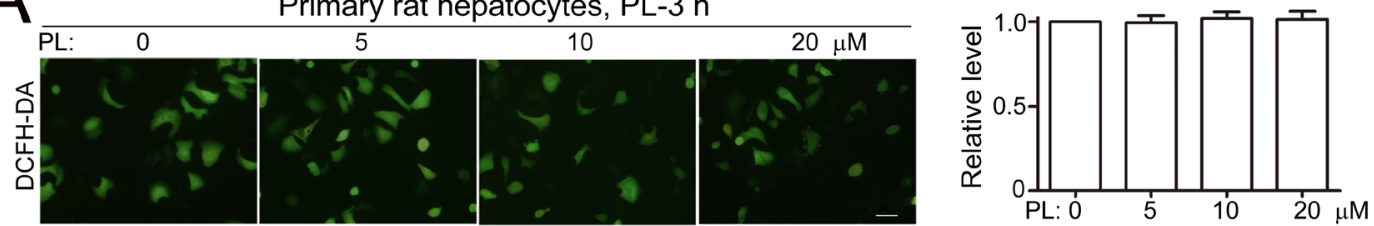

$\mathrm{B}$
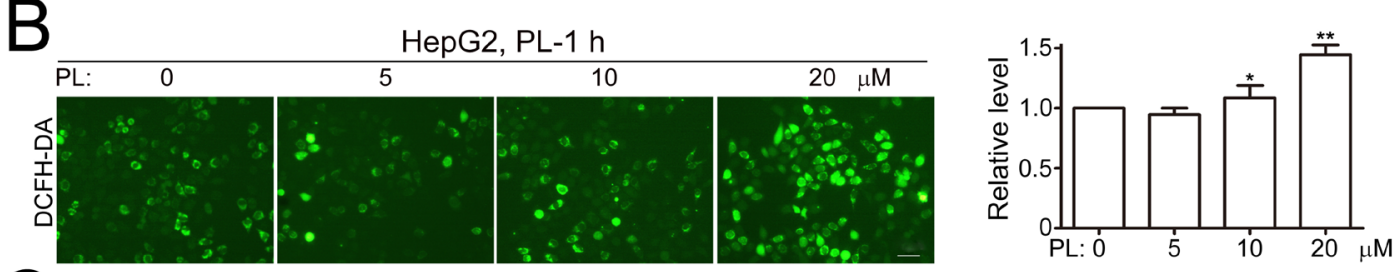

C

Huh7, PL-1 h
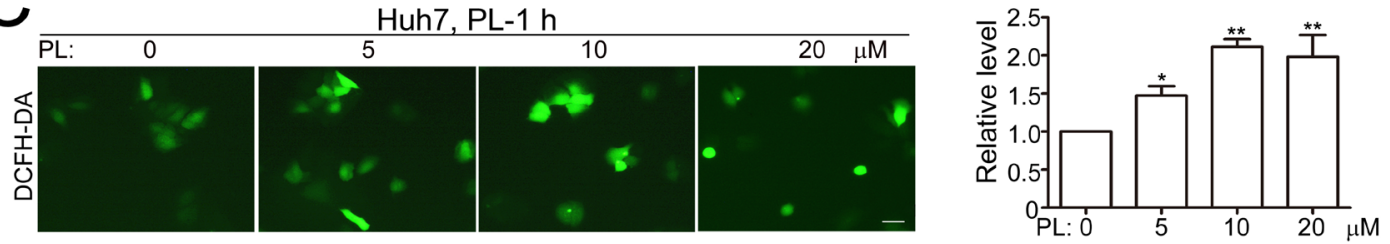

D
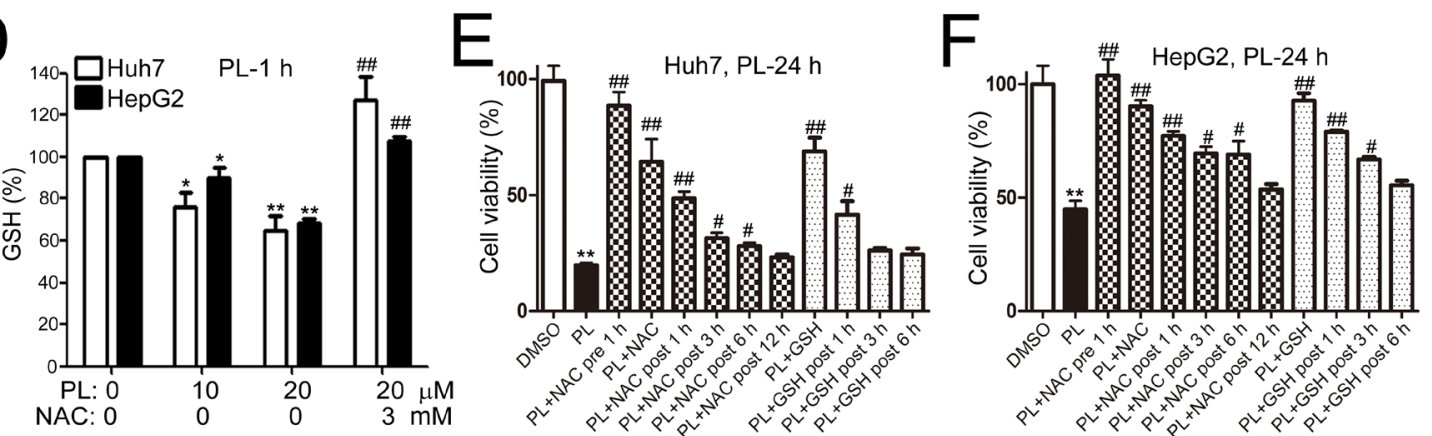

G
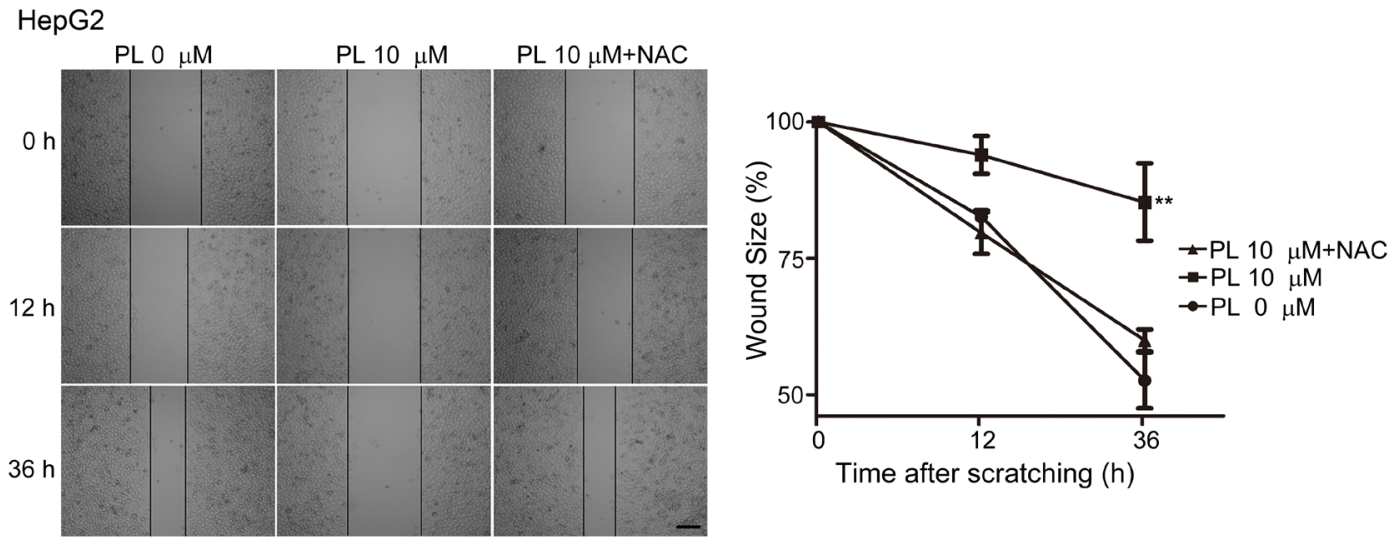

Figure 3: Piperlongumine induced ROS accumulation to kill and suppress HCC cell migration. (A) Effects of PL on the ROS level in primary rat hepatocytes. Cultured primary rat hepatocytes were treated with PL and stained with DCFH-DA. Bar, $20 \mu \mathrm{m}$. Representative micrographs showed that the fluorescent intensity of DCFH-DA was not altered within $3 \mathrm{~h}$ after PL treatment. For statistical analysis, the mean DCFH-DA fluorescent intensity (representing cellular ROS level) was measured from 9 random fields for each culture. All values represented mean \pm SEM of three independent experiments. (B-C) Effects of PL on the ROS level in HepG2 (B) and Huh7 (C) cells. Bar, $20 \mu \mathrm{m} .{ }^{*} P<0.05$ and $* * P<0.01 v s$. corresponding PL $0 \mu \mathrm{M}(\mathrm{n}=3)$. (D) Effects of PL on the GSH level in HCC cells. NAC was pretreated for $1 \mathrm{~h}$ and then co-treated with PL for another $1 \mathrm{~h}$. ${ }^{*} P<0.05$, ${ }^{*} P<0.01$ vs. PL $0 \mu \mathrm{M}$ control. ${ }^{*} P<0.01$ vs. corresponding PL 20 $\mu \mathrm{M}$ control. (E-F) Effects of antioxidants on PL-induced cytotoxicity in Huh7 (E) and HepG2 (F) cells. NAC (3 mM) or GSH (5 mM) was administrated either before PL $(20 \mu \mathrm{M})$ administration (PL+NAC pre), simultaneously with PL (PL+NAC/GSH) or after PL treatment (PL+ NAC/GSH post). Cell viability was measured by MTT assays. ${ }^{* *} P<0.01 v s$. DMSO control; ${ }^{\#} P<0.05$ or ${ }^{\#} P<0.01 v s$. PL $20 \mu \mathrm{M}$ control $(\mathrm{n}=3)$. (G) Effects of NAC on PL-suppressed HepG2 cell migration after cell scratching. NAC (3mM) was administrated simultaneously with PL after cell scratching. Bar, $100 \mu \mathrm{m} .{ }^{* *} P<0.01 v s$. PL $0 \mu \mathrm{M}$ or PL $10 \mu \mathrm{M}+\mathrm{NAC}(\mathrm{n}=3)$. 


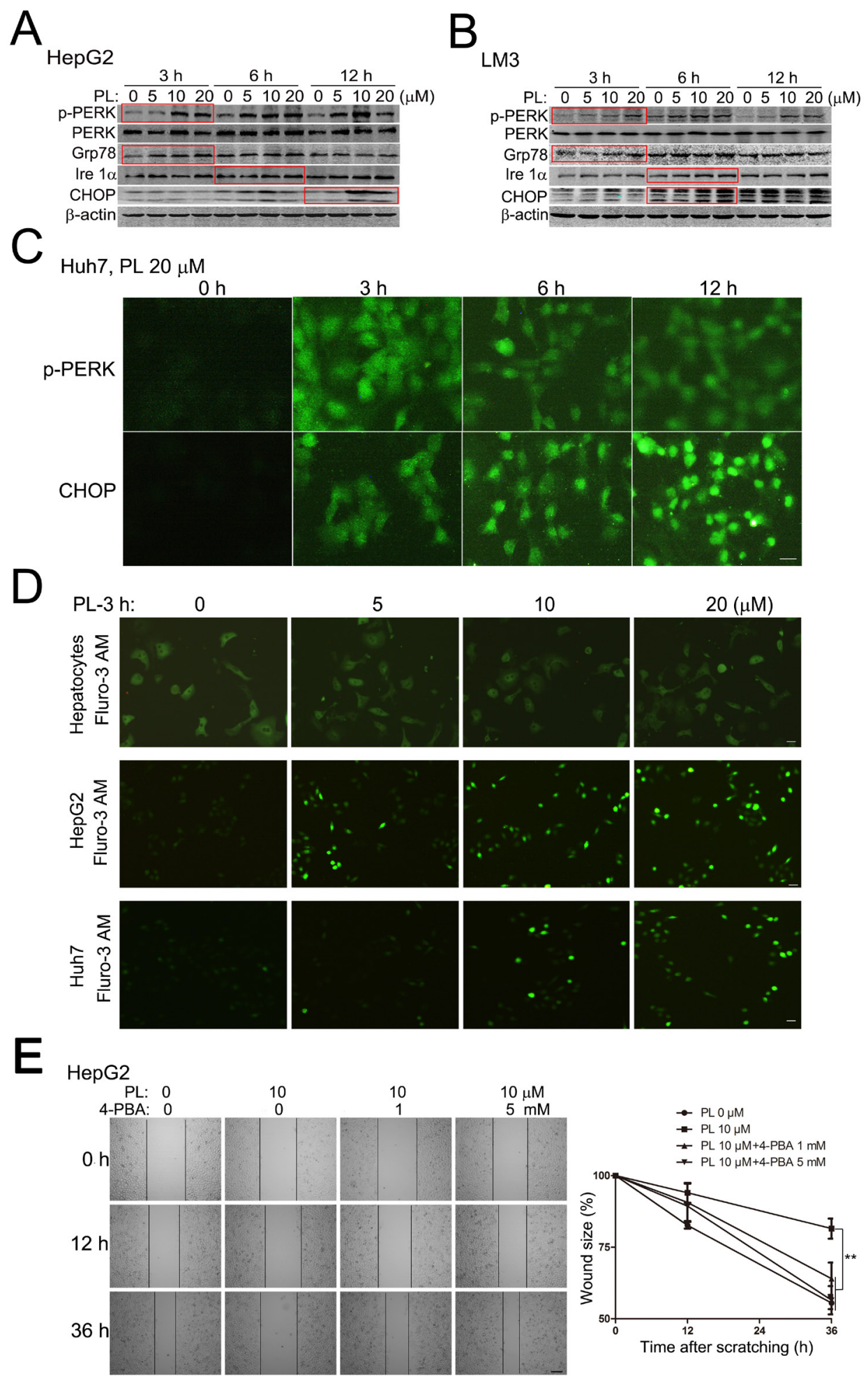

Figure 4: Piperlongumine induced ER stress-responses to suppress HCC cell migration preferentially. (A-B) Representative results of Western blotting analysis of specific ER stress-response proteins in PL-treated HepG2 (A) and LM3 (B) cells. HepG2 or LM3 cells were treated with $0,5,10$ and $20 \mu \mathrm{M}$ of PL for 3, 6 or $12 \mathrm{~h}$. Equal amounts of total proteins were subjected to Western blotting analysis with designated antibodies. The red box indicated the most evident changes of p-PERK, Grp78, Ire 1 $\alpha$ or CHOP in PLtreated HepG2 (A) and LM3 (B) cells. (C) Representative micrographs of fluorescent immunostaining showed PL (20 $\mu$ M) activated p-PERK and up-regulated CHOP in Huh7 cells. Bar, $20 \mu \mathrm{m}$. (D) Representative fluorescent micrographs of Fluro-3AM showed that PL enhanced free calcium concentration in PL-treated HepG2 or Huh7 cells but not primary rat hepatocytes. Bar, $20 \mu \mathrm{m}$. (E) Effects of ER stress-response inhibitor 4-PBA on PL-suppressed HepG2 cell migration after cell scratching. Bar, $100 \mu \mathrm{m} .{ }^{* *} P<0.01(\mathrm{n}=3)$. 
reversing effects of 4-PBA on PL's effects on HCC cell migration were close to those of NAC, suggesting that PL inhibited HCC cell migration or invasion via ROS-ERmediated signaling preferentially.

\section{Piperlongumine activates MAPKs signaling pathways which preferentially suppress HCC migration}

MAPKs are canonical ROS- and ER-stress responsive signaling pathways that control cell death under oxidative stress [31, 32]. Results of Western blotting analysis showed prominent activation of p38, JNK and Erk in HepG2 (Fig. 4A) and LM3 (Fig. 4B) cells at various time points of PL treatment in a dose-dependent manner $(0,5,10$ or $20 \mu \mathrm{M})$. We then examined whether the activation of MAPKs contributed to PL's anti-cancer effects in HCC cells. Pharmacological inhibition of p38, JNK or Erk signaling pathway by using corresponding inhibitor SB203580, SP600125 or U0126 did not alter PL's effects on cell death in HepG2 (Fig. 5C) or LM3 cells (Fig. 5D). However, suppressing p38 (SB203580), JNK (SP600125) or Erk (U0126) signaling pathway prominently reversed PL's effects on HepG2 cell migration at 24 or $48 \mathrm{~h}$ after cell scratching (left panels, Fig. 5E). Statistical analysis demonstrated that the wound sizes were significantly increased in SB203580/ SP600125/ U0126 plus PL $10 \mu \mathrm{M}$ treatment groups as compared to that in PL $10 \mu \mathrm{M}$ treatment group in HepG2 cells (right panel, Fig. 5E). These evidences suggested that the activation of MAPKs mainly contributed to PL's effect on cell migration.

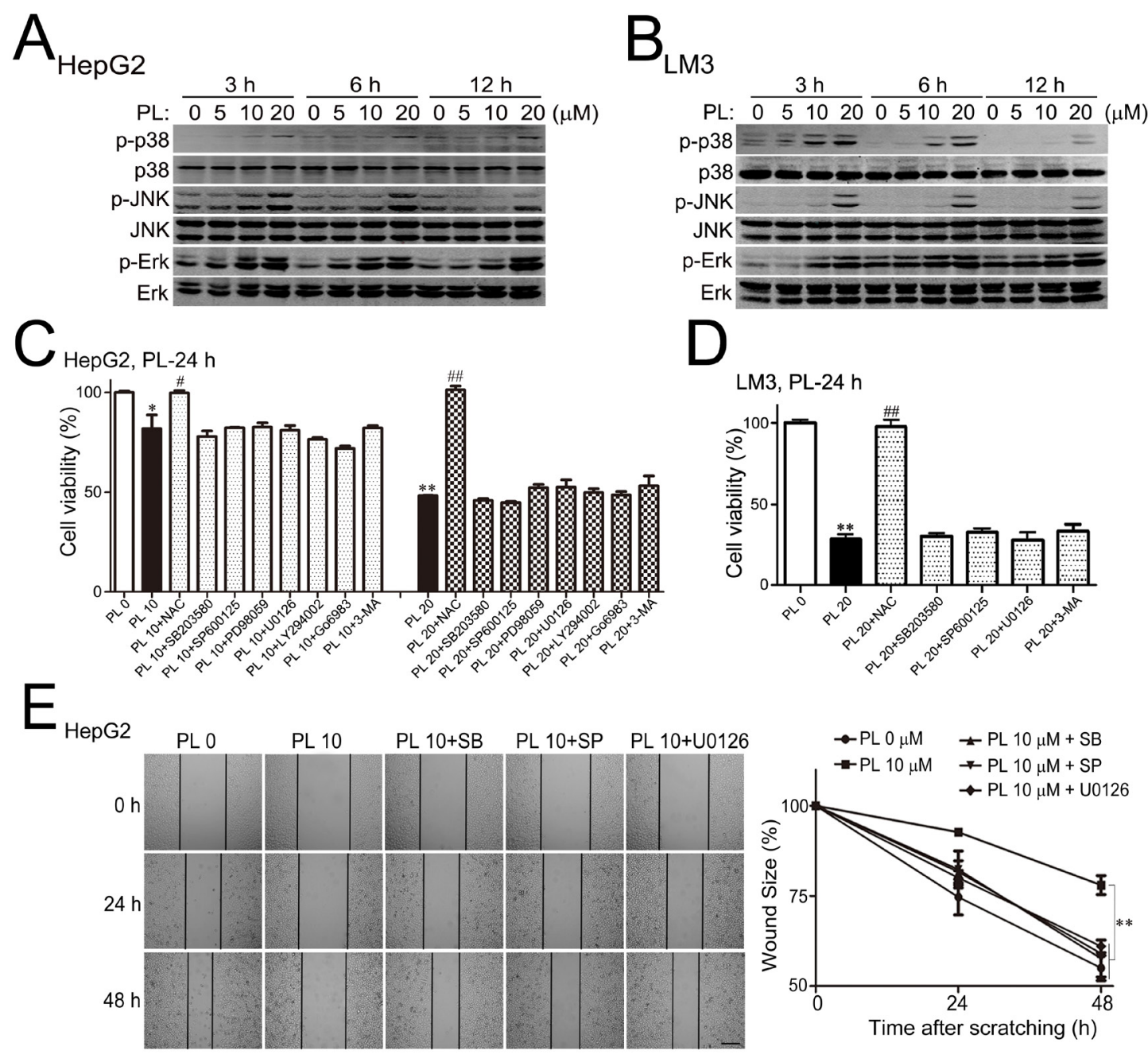

Figure 5: Piperlongumine activated MAPKs to suppress HCC cell migration preferentially. (A-B) Representative results of Western blotting analysis demonstrated that p38, JNK and Erk were prominently activated in PL-treated HepG2 (A) and LM3 (B) cells in a dosage-dependent manner. (C-D) Effects of specific inhibitors on the cell viability in PL-treated HepG2 (C) and LM3 (D) cells as measured by MTT assays. PL were administrated alone or together with other drugs (i.e., SB203580 $10 \mu \mathrm{M}$, SP600125 $10 \mu \mathrm{M}$, PD98059 $10 \mu \mathrm{M}$, LY294002 $10 \mu \mathrm{M}$, U0126 $10 \mu \mathrm{M}$, Go6983 $10 \mu \mathrm{M}$ or 3-MA $10 \mu \mathrm{M})$. ${ }^{*} P<0.05$, ${ }^{* *} P<0.01$ vs. PL 0 ; ${ }^{\#} P<0.05$, ${ }^{\#} P<0.01$ vs. corresponding PL $20(n=3)$. (E) Effects of specific MAPKs inhibitors on PL-suppressed HepG2 cell migration after cell scratching. PL (10 $\mu$ M) was administrated together with $10 \mu \mathrm{M}$ of SB203580, SP600125 or U0126. Bar, $100 \mu \mathrm{m}$. ${ }^{* *} P<0.01$ (n=3). 


\section{Piperlongumine functions through ROS-ER- MAPKs-CHOP axis in $\mathrm{HCC}$ cells}

We then verified the existence of ROS-ERMAPKs-CHOP axis in PL-treated HCC cells by using the corresponding inhibitors. Results of Western blotting analysis showed that co-incubation of antioxidant NAC with PL completely abolished PL-activated PERK (Fig. $6 \mathrm{~A}$, indicated by the rectangular box) and $\mathrm{p} 38 / \mathrm{JNK} / \mathrm{Erk}$ (Fig. 6B), and PL-up-regulated Ire $1 \alpha$ and CHOP (Fig. 6A) in HepG2 cells at various time points of PL treatment.
The ER stress inhibitor 4-PBA showed similar inhibitory effects on ER-MAPKs-CHOP signaling pathways compared to NAC (Fig. 6A and 6B). Consistently, results of fluorescent cytoimmunostaining assay also showed that NAC and 4-PBA evidently reduced the elevated level of p-PERK (Supplemental Fig. 4B) or CHOP by PL (Fig. $6 \mathrm{C})$ at various time points of PL treatment in HepG2 cells. Further, suppressing $\mathrm{p} 38 / \mathrm{JNK} /$ Erk signaling pathways by SB203580/SP600125/U0126 correspondingly evidently reduced PL-elevated CHOP at 6 or $12 \mathrm{~h}$ of PL treatment in HepG2 cells (Fig. 6C). These evidences demonstrated that $\mathrm{PL}$ activated ER-MAPKs-CHOP axis signaling pathways
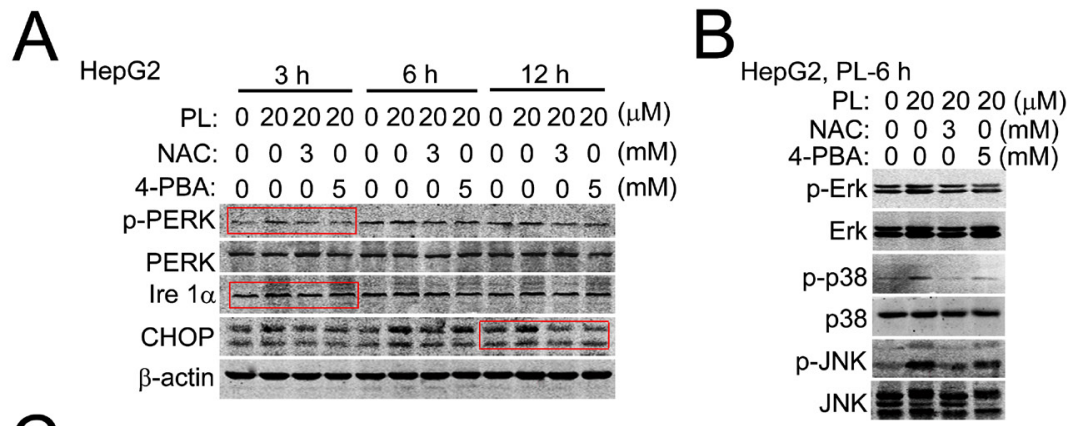

$\mathrm{C}_{\text {HepG2 }}$
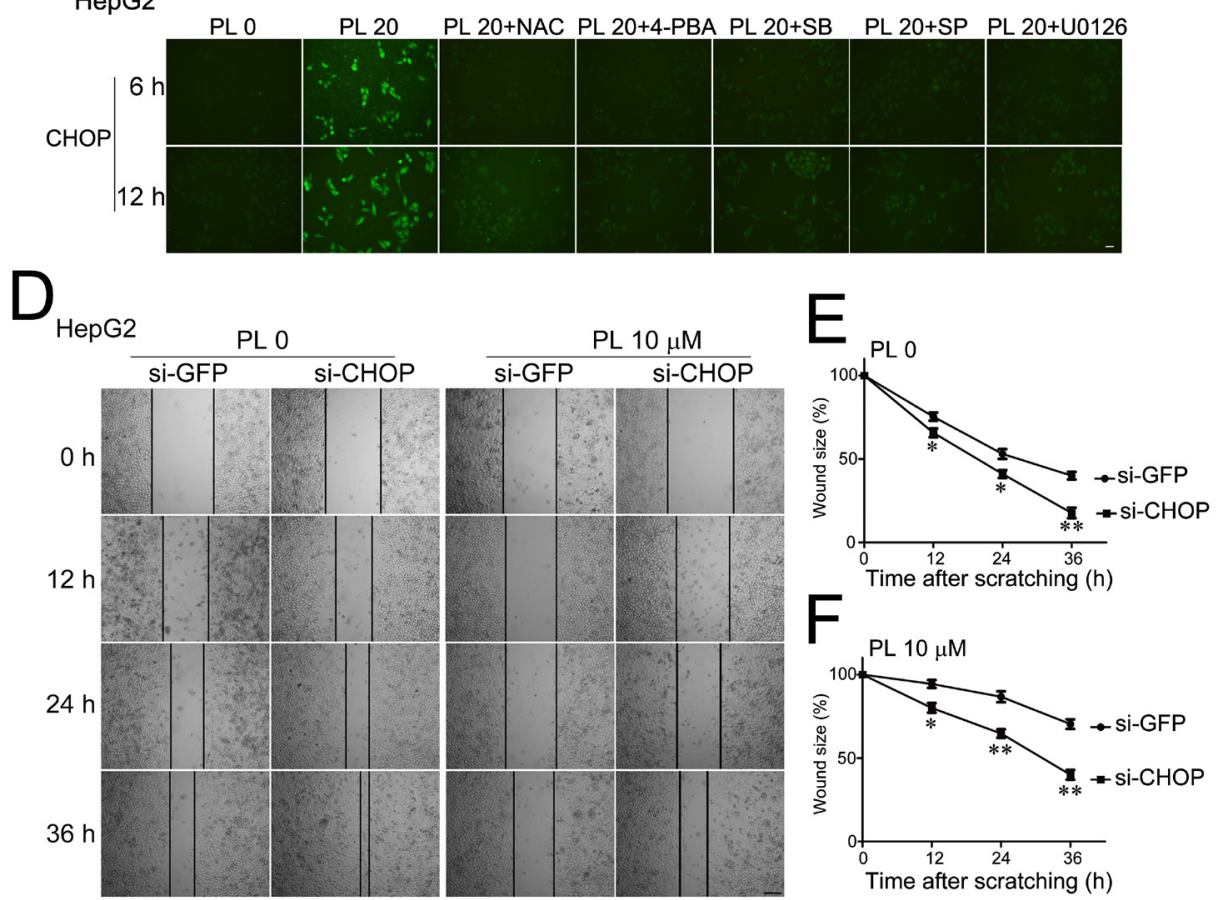

Figure 6: Piperlongumine suppressed HCC cell migration via ROS-ER-MAPKs-CHOP signaling pathway. (A) Representative results of Western blotting analysis showed the effects of NAC or 4-PBA on the expression of specific ER stress-response proteins (p-PERK/PERK, Ire $1 \alpha$ and CHOP) in PL-treated HepG2 cells. The red boxes indicated the most evident reversal effect of NAC or 4-PBA. (B) Representative results of Western blotting analysis showed the effects of NAC or 4-PBA on the activation of p38/JNK/Erk. (C) Representative micrographs of fluorescent cytoimmunostaining showed the effects of NAC, 4-PBA or MAPKS inhibitors on CHOP expression in PL-treated HepG2 cells. Bar, $20 \mu \mathrm{m}$. (D) Effects of knocking-down CHOP by RNA interference on HepG2 cell migration. HepG2 cells were transfected with small interfering RNA specific for CHOP (si-CHOP) for 2 days and then subjected to cell scratching and PL treatment. Small interfering RNA specific for green fluorescent protein (si-GFP) was used as non-specific control. Bar, $100 \mu \mathrm{m}$. (E) and (F) Statistical analyses demonstrated that silencing CHOP (si-CHOP) significantly accelerated the speed of wound-healing of HepG2 cells after scratching without (E) or with PL treatment (F). ${ }^{*} P<0.05,{ }^{*} P<0.01$ vs. corresponding si-GFP $(\mathrm{n}=3)$. 
via ROS-dependent mechanisms.

Finally, we examined the role of CHOP in HCC cell migration by knocking-down CHOP via small RNA interference technique. Transfection of small interfering RNA specific to CHOP (si-CHOP) [30] effectively reduced the expression of endogenous CHOP in HepG2 cells (Supplemental Fig. 7A) but did not affect the viability of HepG2 cells (MTT assay) at $24 \mathrm{~h}$ of PL treatment (Supplemental Fig. 7B). However, transfection of si-CHOP evidently accelerated HepG2 cell migration at various time points $(12,24$ and $36 \mathrm{~h})$ after cell scratching as compared to corresponding si-GFP (green fluorescent protein) controls (Fig. 6D). Statistical analysis demonstrated that knocking-down of CHOP (si-CHOP) significantly reduced the wound-size of HepG2 culture at various time points after scratching without or with PL treatment (PL 0, Fig. 6E and PL $10 \mu \mathrm{M}$, Fig. 6F) as compared to corresponding si-GFP controls. These results supported that CHOP was required for suppressing HCC cell migration and was a critical downstream target of PL's action in HCC cell migration.

\section{Piperlongumine activates ER-MAPKs-CHOP axis signaling and reduces $\mathrm{HCC}$ in vivo}

After clarifying the anticancer effects and mechanisms of PL in HCC cells in vitro, we examined the role of PL in HCC-bearing mice. Equal amount of murine ascetic $\mathrm{H} 22$ hepatoma cells was subcutaneously inoculated into the flank side of adult male Kunming mice [33-35]. After $24 \mathrm{~h}$ of inoculation, PL was administrated once a day by intraperitoneal (i.p.) injection for 14 days consecutively and then tumor xenografts were isolated. Fig. 7A showed that the tumor xenografts from PL-treated groups were evidently smaller than those from DMSO control group. Statistical analysis demonstrated that the average volume (Fig. 7B) and weight (Fig. 7C) of the tumor xenografts from PL treatment groups were both significantly decreased as compared to that from DMSO control group. Notably, PL at a much lower concentration $(1.5 \mathrm{mg} / \mathrm{kg})$ showed a comparable anticancer effect in HCC-bearing mice and increasing PL concentration did not significantly enhance its anticancer effects (Fig. 7A, 7B and 7C).

Consistent with in vitro assays, results of Western blotting analysis demonstrated that PL significantly activated p-PERK and up-regulated Ire $1 \alpha$, PDI, and CHOP in H22 tumor xenografts (Fig. 7D). Meanwhile, MAPKs (i.e., p38, JNK and Erk) were significantly activated in $\mathrm{H} 22$ tumor xenografts (Fig. 7E). These results verified that the ER-MAPKs-CHOP signaling pathway was activated by PL in HCC cells in vivo.

\section{DISCUSSION}

In the present study, we demonstrated that
PL selectively killed HCC cells and inhibited their migration and invasion. PL activated ROS-ER-MAPKsCHOP signaling axis prominently, which consequently suppressed HCC cell migration/invasion preferentially.

We demonstrated that PL was a selective anti-cancer drug for HCC. PL effectively induced cell death in various HCC cell lines including the highly malignant LM3 cells [33] with an $\mathrm{IC}_{50}$ of $10-20 \mu \mathrm{M}$ but had little cytotoxicity in normal hepatic cells under similar conditions (Fig. 1). The cytotoxic efficacy of PL in HCC cells was similar to that in glioblastoma multiforme (GBM) cells [9], suggesting a general selective cytotoxicity of PL in those highly malignant cancers. In addition, PL selectively suppressed HCC migration/invasion but did not affect the migration of normal hepatic cells (Fig. 2). Notably, PL at a lower concentration $(2.5-10 \mu \mathrm{M})$ exhibited a remarkable effect on suppressing HCC cell migration in scratched cultures in which PL-induced cell death was negligible (Fig. 2), suggesting a major anti-cancer effect of PL on suppressing metastasis. This is particularly important for the treatment of highly malignant tumors such as HCC since metastasis is the major cause of death [1-3]. Consistent with the anticancer effects of PL in vitro assays, PL was effective in reducing $\mathrm{HCC}$ development in mice (Fig. 7). PL might suppress $\mathrm{HCC}$ development in vivo via inducing cell death, suppressing cell migration/invasion and reducing tumor vessel formation (Supplemental Fig. 8). PL at $1.5-3.5 \mathrm{mg} / \mathrm{kg} / \mathrm{d}$ showed comparable anticancer effects in HCC xenograft-bearing mice, suggesting that the therapeutic effects of PL in vivo reached a plateau at the dosage around $1.5 \mathrm{mg} / \mathrm{kg} / \mathrm{d}$ and that further increasing the dosage of PL might not improve PL's therapeutic effect much due to the limited effective drug concentration in cancer tissues, the varied sensitivity of cancer cells to drug, the complicated feedback drug-resistant mechanisms or the increased side effects of drug in vivo. Since PL is a natural product which has been already used in traditional medicines for a thousand years $[12,13]$, it is practical to apply PL to the treatment of the highly malignant HCC clinically.

Our data clearly demonstrated that the ROS accumulation was a major initial factor responsible for PL's anticancer effects in HCC as pre-treatment of antioxidants completely abolished PL-induced cytotoxicity in $\mathrm{HCC}$ cells while delayed administration of antioxidants (3-12 h post PL treatment) markedly reduced their efficacy in antagonizing PL's cytotoxicity (Fig. 3E). Previous studies mainly focus on the cytotoxic effects of PL in cancer cells and various ROS-dependent cell death mechanisms, e.g., apoptosis [36-38], autophagic cell death $[16,39]$, cell cycle arrest $[17,38]$, GSTP1 [13], p38 [9, 39], JNK [9, 38], Erk [15], which have been proposed in different cancer cell lines. Until now, however, the exact molecular mechanisms of PL's action in cancer cells remain largely unclear, probably reflecting the nature of non-specific ROS stimulation in multiple signaling 


\section{A}

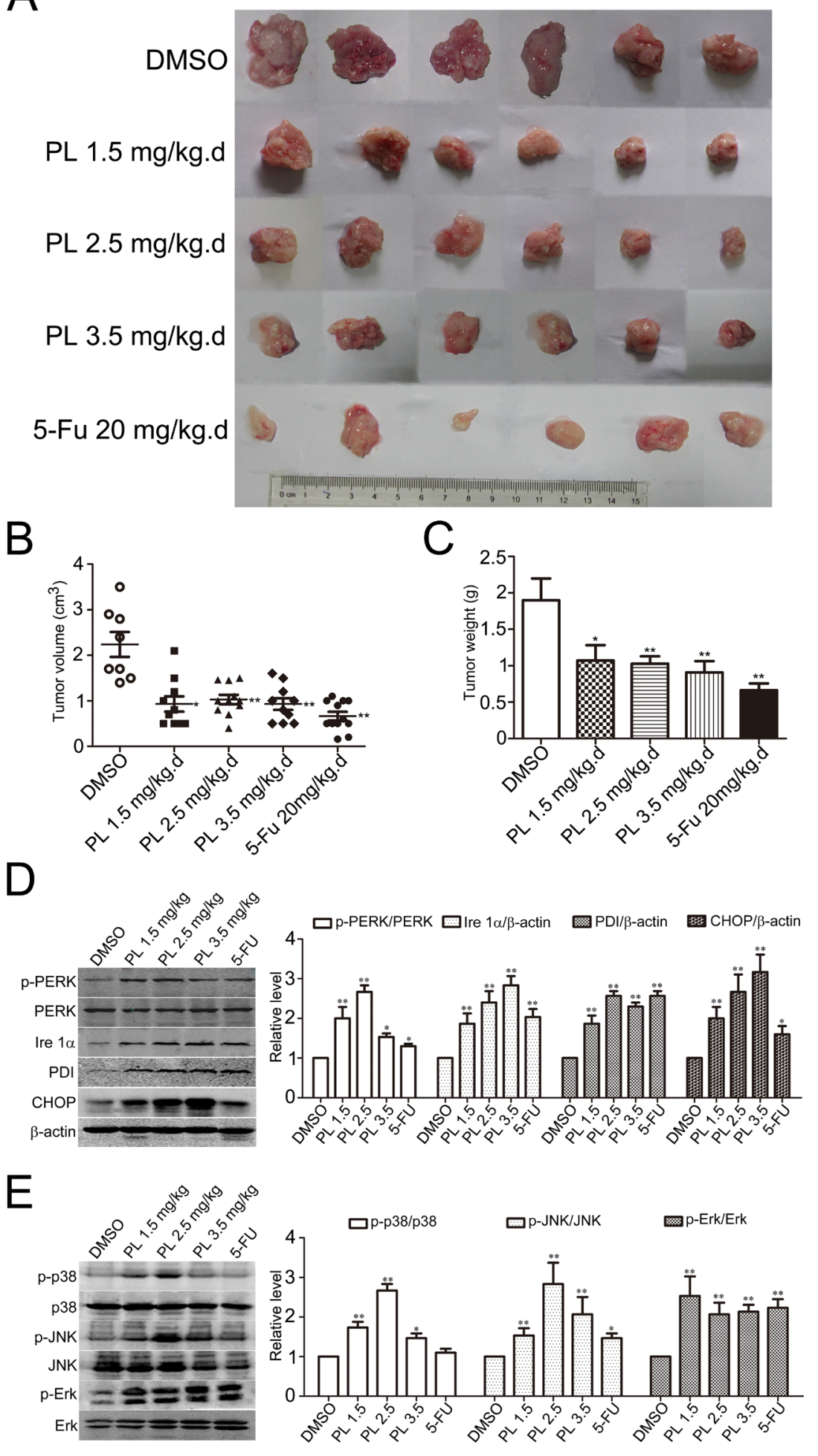

Figure 7: Piperlongumine suppressed HCC development and activated ER-MAPKs-CHOP signaling pathway. (A) Representative inoculated HCC tumors from mice treated with PL. Equal amounts of H22 cells were subcutaneously injected into the left flank of adult mice. PL, 5-Fu or DMSO was administrated for 14 days (once per day) and then the tumor xenografts were removed completely from tissues. (B-C) Statistical analyses demonstrated that the average volume (B) and weight (C) of HCC xenografts from PL-treated mice were significantly reduced. ${ }^{*} P<0.05,{ }^{*} P<0.01 v$. DMSO group $(\mathrm{n}=8)$. (D) Representative Western blotting analysis and statistical analysis of p-PERK/PERK, Ire $1 \alpha$, PDI and CHOP from xenografts. ${ }^{*} P<0.05,{ }^{*} P<0.01 v$ s. corresponding DMSO control ( $\mathrm{n}=5$ ). (E) Representative Western blotting analysis and statistical analysis of p-p38/p38, p-JNK/JNK and p-Erk/Erk from xenografts. ${ }^{*} P<0.05$, ** $P<0.01$ vs. corresponding DMSO control ( $\mathrm{n}=5)$. 
pathways and the complicated regulatory mechanisms involving in cell death process [5-9]. In HCC cells, the PL-induced cytotoxicity could not be efficiently reduced by a single signaling pathway inhibitor except antioxidants, suggesting that multiple ROS-dependent cell death mechanisms are involved in PL's cytotoxicity in HCC cells.

Unlike the elusive cell-death mechanisms underlying PL's action, we clarified a key signaling pathway (i.e., ROS-ER-MAPKs-CHOP) which was preferentially responsible for PL's action on HCC cell migration/invasion. Different from previous studies which showed a differentially activation of p38, JNK and Erk in distinct cancer cells $[9,10,15]$, we demonstrated that PL induced prominent activation of all the three major MAPKs signaling pathways including p38, JNK and Erk in HCC cells, supporting that MAPKs were major ROSstress responsive signaling pathways upon PL treatment. It is well-known that ER is a major organelle responsible for ROS accumulation [20] and MAPKs are canonical downstream signaling pathways of ER stress-responses [21]. Indeed, ROS-dependent activation of PERK, release of $\mathrm{Ca}^{2+}$ and induction of Ire $1 \alpha$ were prominent in HCC cells upon PL treatment (Fig. 4). Inhibition of ER stressresponses by 4-PBA suppressed PL-activated MAPKs (Fig. 6), supporting that PL activated the MAPKs via ER stress-responses in HCC cells. CHOP is a key ER stressresponse product involved in cell death [21]. Interestingly, suppressing ER-MAPKs-CHOP signaling axis by either inhibitors (4-PBA, SP, SB, or U0126) or knockingdown of CHOP did not affect the rate of HCC cell death evidently but showed prominent effects on HCC cell migration, suggesting that PL preferentially suppressed HCC migration/invasion via ER-MAPKs-CHOP. Consistent with PL's effects on HCC cell migration, PL also suppresses cell migration of highly malignant GBM cells via ROS-p38/JNK/NFKB signaling [10]. These evidences suggest that MAPKs might be a signaling hub for PL's suppressed effects on cell migration/invasion. Further dissecting the molecular mechanisms underlying PL's effects on cancer cell migration/invasion is important for future applications of PL in cancer therapy.

In summary, we have demonstrated that PL selectively killed HCC cells and suppressed HCC cell migration/invasion. Preferentially, PL suppressed HCC migration/invasion via ROS-ER-MAPKs-CHOP axis signaling. Our data suggest that PL has the prospects of application in the treatment of highly malignant HCC.

\section{METHODS}

\section{Cell culture, reagents and antibodies}

Human HCC cell lines (HepG2, Huh7) and normal hepatic L-02 cells were purchased from ATCC (Manassas, VA, USA). HepG2 and Huh7 were cultured with $10 \%$ FBS in DMEM and L-02 was cultured with $10 \%$ FBS in RPMI-1640. Highly malignant human HCC LM3 cells were obtained from Zhongshan Hospital, Fudan University and cultured with $15 \%$ FBS in DMEM [40]. Mouse HCC cell line H22 was purchased from Shanghai SLAC Laboratory Animal Co. Ltd. (Shanghai, China). Primary cultures of rat hepatocytes were set as reported [41]. Briefly, hepatocytes (cell viability $>85 \%$ ) were isolated from livers of normal male Wistar rats by collagenase perfusion and mechanical disruption, seeded in collagen-coated 96 -well plates with $10 \%$ FBS in highglucose DMEM at a density of $2 \times 10^{4}$ cells $/ \mathrm{cm}^{2}$, and used at day 5 in vitro. All culture media and fetal bovine serum (FBS) were purchased from Gibco/Life Technologies (Carlsbad, CA, USA). Piperlongumine, 5-fluorouracil (5-FU), 4-phenylbutyric acid, Hoechst 33342, propidium iodide, Fluo-3 AM, trypan blue, glutathione, N-acetylL-cysteine (NAC), 2,7-dichlorodihydrofluorescein diacetate (DCFH-DA), 3-(4,5-dimethylthiazol-2-yl)-2,5diphenyltetrazolium bromide (MTT), 3-Methyladenine (3-MA) and crystal violet were purchased from SigmaAldrich (St Louis, MO, USA). SB203580 (p38 pathway inhibitor), SP600125 (JNK pathway inhibitor), U0126 or PD98059 (MEK 1/2 inhibitors), LY294002 (PI-3K inhibitor) and Go6983 (PKC $\zeta$ inhibitor) were purchased from Cell Signaling Technology (Danvers, MA, USA). Annexin V-FITC apoptosis detection kit was purchased from KeyGEN BioTECH (Nanjing, China). Quantification of reduced GSH was conducted by a kit from Nanjing Jiancheng Bioengineering Institute (Nanjing, China). Antibodies against $\beta$-actin were purchased from Santa Cruz Biotechnology (Santa Cruz, CA, USA), and antibodies against Grp78, PDI, p-PERK (Thr981)/PERK, Ire 1 $\alpha$, CHOP, p-p38 (Thr180/Tyr182)/p38, p-JNK (Thr183/Tyr185)/JNK, p-Erk (Thr202/Tyr204)/Erk were from Cell Signaling Technology (Danvers, MA, USA).

\section{Piperlongumine and other drug treatments}

PL was dissolved in dimethyl sulfoxide (DMSO) at a stock concentration of $50 \mathrm{mM}$ and used at designated final concentration $(0-20 \mu \mathrm{M})$ with a maximal DMSO concentration less than $0.5 \%$ DMSO. DMSO of the same concentration in DMEM was used as the vehicle control (i.e., PL 0). NAC, GSH and SB203580/SP600125/U0126 were used at $3 \mathrm{mM}, 5 \mathrm{mM}$ and $10 \mu \mathrm{M}$ respectively. 4-PBA was used at a final concentration ranged from 1-5 mM. 
NAC and other drugs were added simultaneously with PL at designated final concentrations or as indicated.

\section{Cell viability or cell death assays}

Cell viability was determined by MTT assay and cell death was determined by trypan blue exclusion assay or PI staining. For MTT assays, 5000 cells/well were seeded in 96-well plates. After $24 \mathrm{~h}$ of incubation, cells were treated with drugs in six parallel wells for designated times and then assayed with MTT as reported [42, 43]. For trypan blue exclusion assay and PI staining, cells at 60 $70 \%$ confluence in six-well plates were treated with drugs in triplicates for $24 \mathrm{~h}$ and then subjected for corresponding assays.

\section{Flow cytometry assay}

FCM assay was employed to analyze apoptosis and cell cycle as previously reported [9]. HCC cells were treated with PL for $24 \mathrm{~h}$ and co-stained with annexin V-FITC and PI according to the manufacturer's instructions (KeyGEN BioTECH). Apoptotic cells were separated and quantified by a FACSCalibur Flow Cytometry System (Becton Dickinson, San Jose, CA, USA). For cell cycle assay, HCC cells were treated with PL for $24 \mathrm{~h}$ and stained with PI [10].

\section{Scratch-wound healing assay}

Cell migration after scratching was performed as reported previously [10]. Briefly, confluent cells in $35-\mathrm{mm}$ dishes were scratched with $200-\mu 1$ pipette tips. Immediately after cell scratching, the wounded edges were micrographed (designated as $0 \mathrm{~h}$ ). Scratched cells were then incubated with fresh complete media with appropriate concentration of drugs and the wounded edges were micrographed at designated time points. The wound size (i.e., the gap between the two opposite wounded edges) was calculated using the Image-Pro Plus software (Media Cybernetics, USA) and the average of wound size represented at least 12 different fields in each culture dish. Relative wound sizes of designed time points after scratching were compared to that of $0 \mathrm{~h}$ control.

\section{Transwell migration and invasion assays}

Transwell migration and invasion assays were performed as reported [10, 44]. Briefly, HepG2 cells $\left(1 \times 10^{5}\right.$ cells/well $)$ were seeded into the upper chamber of a transwell apparatus with a $8-\mu \mathrm{m}$ pore size membrane (Corning Incorporated, Corning, NY, USA) in $200 \mu 1$ of serum-free DMEM containing drugs. For the invasion assay, the upper chamber was pre-coated with matrigel basement membrane matrix (BD Bioscience, Bedford, MA, USA) according to the manufacturer's protocols. For both assays, the medium of lower chamber contained $800 \mu \mathrm{l}$ of complete medium. After $24 \mathrm{~h}$, the migrated or invaded cells at the lower surface of the filter were stained, micrographed and calculated as reported previously [10]. The average migrated/invaded cell number represented at least nine different fields in each filter.

\section{Measurement of intracellular ROS and reduced glutathione (GSH)}

Intracellular ROS level was measured using DCFHDA as reported previously $[9,10]$. Briefly, PL-treated cells were incubated with $10 \mu \mathrm{M}$ of DCFH-DA for $30 \mathrm{~min}$ at $37^{\circ} \mathrm{C}$, washed twice with PBS and then micrographed with a conventional fluorescent microscope (Olympus, Tokyo, Japan). For each culture, a minimum of 9 random fields were captured. Average fluorescent intensity was analyzed using the Image-Pro Plus software (Media Cybernetics, USA). For GSH measurement, PL-treated HepG2 or Huh7 cells were washed with ice-cold PBS three times, scrapped off from the plates and subjected to sonification. The supernatants were collected and reduced GSH was calculated according to the manufacturer's instructions (Nanjing Jiancheng Bioengineering Institute).

\section{Western blotting analysis and fluorescent cytoimmunostaining}

Western blot analysis and fluorescent cytoimmunostaining were performed as described previously [45]. Briefly, equal amounts of total proteins were subjected to mini-PAGE gel electrophoresis and transferred to NC membranes. The blots were incubated with corresponding primary and fluorescent secondary antibodies. The bands were quantified using the Odyssey Infrared Imaging System (LI-COR Bioscience, Lincoln, NE, USA). $\beta$-actin was used as internal control. For fluorescent cytoimmunostaining, PL-treated cells in the $35-\mathrm{mm}$ culture dishes were fixed, permeabilized, blocked, and then incubated with corresponding primary and Dylight 488-labeled secondary antibodies (Abbkine, Redlands, CA, USA). Micrographs were taken under the same conditions with a conventional fluorescent microscope (Olympus, Tokyo, Japan).

\section{Intracellular $\mathrm{Ca}^{2+}$ measurements}

Intracellular $\mathrm{Ca}^{2+}$ levels were detected with Fluo-3 $\mathrm{AM}$ as reported [46]. PL-treated cells were washed with $\mathrm{Ca}^{2+}$-free PBS three times and then incubated with $5 \mu \mathrm{M}$ of Fluo-3AM for $30 \mathrm{~min}$. After brief rinse with $\mathrm{Ca}^{2+}$-free PBS, living cells were micrographed immediately under 
a conventional fluorescent microscope (Olympus, Tokyo, Japan).

\section{RNA interference}

Small interfering RNA for CHOP (5'-GGUAUGAGGACCUGCAAGA-3', si-CHOP) was chemically synthesized (Guangzhou RiboBio Co., Ltd., Guangzhou, China) and non-specific control si-GFP was provided by Guangzhou RiboBio. Twenty-four hours after cell seeding, interfering RNAs at $50 \mathrm{nM}$ were transfected into HepG2 cells using Lipofectamine 2000 (Invitrogen, Carlsbad, CA, USA) as previously reported [45]. Two days after siRNA trensfection, the cultures were subjected to PL treatment and the corresponding assays.

\section{Hepatocarcinoma 22 (H22)-derived solid HCC in mice}

Specific pathogen-free male Kunming mice with body weights of $18-22 \mathrm{~g}$ were purchased from the Experimental Animal Centre, Huazhong University of Science and Technology (HUST). All the mice were housed in a clean environment and had free access to standard rodent diet and water at room temperature and a humidity of $45-55 \%$. All the animal experimental procedures are approved by the Animal Care and Use Committee of Tongji Medical College, HUST. H22derived solid HCC in mice was generated by injecting $2 \times 10^{7} \mathrm{H} 22$ cells (in $0.2 \mathrm{ml}$ of PBS) into the left armpits of mice as described [47]. Twenty-four hours after initial $\mathrm{H} 22$ inoculation, 50 mice were randomly divided into five groups (i.e., DMSO, PL $1.5 \mathrm{mg} / \mathrm{kg}$.day, PL $2.5 \mathrm{mg} / \mathrm{kg}$.day, PL $3.5 \mathrm{mg} / \mathrm{kg}$.day and 5-FU $20 \mathrm{mg} / \mathrm{kg}$.day; 10 mice/group) and PL or 5-Fu was delivered as designated by i.p. once per day for 14 days consecutively. H22-derived tumor xenografts were harvested, measured and weighted on the $15^{\text {th }}$ day of $\mathrm{H} 22$ inoculation as described previously [43].

\section{Statistical analyses}

All experiments were repeated independently at least three times. The values were expressed as mean \pm SEM and statistics were performed with a 2-way ANOVA followed by the Student-Newman-Keuls test. $P$ values of less than 0.05 were considered statistically significant.

\section{ACKNOWLEDGMENTS}

This work was supported by grants from the National Nature Science Foundation of China (Grant No. 81172397, 81471386) and the Fundamental Research Funds for the Central Universities, HUST (No. 2013ZHYX017) to X.Q. Chen and the China Postdoctoral
Science Foundation (No. 2013M542026) to F Pan.

\section{CONFLICT OF INTEREST}

\author{
None declared.
}

\section{Abbreviations}

4-PBA, 4-phenylbutyric acid; 5-FU, 5-fluorouracil; CHOP, C/EBP homologous protein; DCFH-DA, 2'-,7'-Dichlorofluorescin diacetate; 3-MA, 3-Methlylaclenine; DMEM, Dulbecco's modified Eagle's medium; DMSO, dimethyl sulfoxide; ER, endoplasmic reticulum; Erk, extracellular signal-regulated kinase; FBS, fetal bovine serum; FCM, flow cytometry; GFP, green fluorescent protein; Grp78, glucose-regulated protein 78; GSH, glutathione; HCC, hepatocellular carcinoma; JNK, c-Jun N-terminal kinase; $\mathrm{IC}_{50}$, half maximal (50\%) inhibitory concentration; i.p., intraperitoneal; Ire $1 \alpha$, inositol-requiring enzyme 1 alpha; MAPKs, mitogenactivated protein kinases; MTT, 3-(4,5-Dimethylthiazol2-yl)-2,5-diphenyltetrazolium bromide; NAC, N-acetyl-Lcysteine; NFкB, nuclear factor kappa B; PBS, phosphate buffered saline; PDI, protein disulfide isomerase; PERK, PKR-like ER kinase; PI, propidium iodide; PL, piperlongumine; ROS, reactive oxygen species; siRNA, small interfering RNA.

\section{REFERENCES}

1. Lozano R, Naghavi M, Foreman K, Lim S, Shibuya K, Aboyans V, Abraham J, Adair T, Aggarwal R, Ahn SY, Alvarado M, Anderson HR, Anderson LM, Andrews $\mathrm{KG}$, Atkinson C, Baddour LM, et al. Global and regional mortality from 235 causes of death for 20 age groups in 1990 and 2010: a systematic analysis for the Global Burden of Disease Study 2010. Lancet. 2012; 380(9859):20952128.

2. Frau M, Feo F and Pascale RM. Pleiotropic effects of methionine adenosyltransferases deregulation as determinants of liver cancer progression and prognosis. $\mathrm{J}$ Hepatol. 2013; 59(4):830-841.

3. Aravalli RN, Steer CJ and Cressman EN. Molecular mechanisms of hepatocellular carcinoma. Hepatology. 2008; 48(6):2047-2063.

4. Zender L, Villanueva A, Tovar V, Sia D, Chiang DY and Llovet JM. Cancer gene discovery in hepatocellular carcinoma. J Hepatol. 2010; 52(6):921-929.

5. Liao YJ, Bai HY, Li ZH, Zou J, Chen JW, Zheng F, Zhang JX, Mai SJ, Zeng MS, Sun HD, Pu JX and Xie D. Longikaurin A, a natural ent-kaurane, induces G2/M phase arrest via downregulation of Skp2 and apoptosis induction through ROS/JNK/c-Jun pathway in hepatocellular carcinoma cells. Cell Death Dis. 2014; 5:e1137. 
6. Ma Y, Zhang J, Zhang Q, Chen P, Song J, Yu S, Liu H, Liu F, Song C, Yang D and Liu J. Adenosine induces apoptosis in human liver cancer cells through ROS production and mitochondrial dysfunction. Biochem Biophys Res Commun. 2014; 448(1):8-14.

7. Cho MY, Cheong JY, Lim W, Jo S, Lee Y, Wang HJ, Han $\mathrm{KH}$ and Cho H. Prognostic significance of catalase expression and its regulatory effects on hepatitis $\mathrm{B}$ virus $\mathrm{X}$ protein $(\mathrm{HBx})$ in HBV-related advanced hepatocellular carcinomas. Oncotarget. 2014.<epubahead of print $>$

8. Fan C, Zheng W, Fu X, Li X, Wong YS and Chen T. Strategy to enhance the therapeutic effect of doxorubicin in human hepatocellular carcinoma by selenocystine, a synergistic agent that regulates the ROS-mediated signaling. Oncotarget. 2014; 5(9):2853-2863.

9. Liu JM, Pan F, Li L, Liu QR, Chen Y, Xiong XX, Cheng K, Yu SB, Shi Z, Yu AC and Chen XQ. Piperlongumine selectively kills glioblastoma multiforme cells via reactive oxygen species accumulation dependent JNK and p38 activation. Biochem Biophys Res Commun. 2013; 437(1):87-93.

10. Liu QR, Liu JM, Chen Y, Xie XQ, Xiong XX, Qiu XY, Pan F, Liu D, Yu SB and Chen XQ. Piperlongumine inhibits migration of glioblastoma cells via activation of ROSdependent p38 and JNK signaling pathways. Oxid Med Cell Longev. 2014; 2014:653732.

11. Wang Y, Wang JW, Xiao X, Shan Y, Xue B, Jiang G, He Q, Chen J, Xu HG, Zhao RX, Werle KD, Cui R, Liang J, Li YL, Xu ZX. Piperlongumine induces autophagy by targeting p38 signaling.Cell Death Dis. 2013; 4:e824.

12. Bezerra DP, Pessoa C, de Moraes MO, Saker-Neto N, Silveira ER and Costa-Lotufo LV. Overview of the therapeutic potential of piplartine (piperlongumine). Eur $\mathrm{J}$ Pharm Sci. 2013; 48(3):453-463.

13. Raj L, Ide T, Gurkar AU, Foley M, Schenone M, Li X, Tolliday NJ, Golub TR, Carr SA, Shamji AF, Stern AM, Mandinova A, Schreiber SL and Lee SW. Selective killing of cancer cells by a small molecule targeting the stress response to ROS. Nature. 2011; 475(7355):231-234.

14. Bharadwaj U, Eckols TK, Kolosov M, Kasembeli MM, Adam A, Torres D, Zhang X, Dobrolecki LE, Wei W, Lewis MT, Dave B, Chang JC, Landis MD, Creighton CJ, Mancini MA and Tweardy DJ. Drug-repositioning screening identified piperlongumine as a direct STAT3 inhibitor with potent activity against breast cancer. Oncogene. 2014; 0.

15. Randhawa H, Kibble K, Zeng H, Moyer MP and Reindl KM. Activation of ERK signaling and induction of colon cancer cell death by piperlongumine. Toxicol In Vitro. 2013; 27(6):1626-1633.

16. Makhov P, Golovine K, Teper E, Kutikov A, Mehrazin R, Corcoran A, Tulin A, Uzzo RG and Kolenko VM. Piperlongumine promotes autophagy via inhibition of Akt/ mTOR signalling and mediates cancer cell death. Br J Cancer. 2014; 110(4):899-907.
17. Shrivastava S, Kulkarni P, Thummuri D, Jeengar MK, Naidu VG, Alvala M, Redddy GB and Ramakrishna S. Piperlongumine, an alkaloid causes inhibition of PI3 K/ Akt/mTOR signaling axis to induce caspase-dependent apoptosis in human triple-negative breast cancer cells. Apoptosis. 2014; 19(7):1148-1164.

18. Adams DJ, Dai M, Pellegrino G, Wagner BK, Stern AM, Shamji AF and Schreiber SL. Synthesis, cellular evaluation, and mechanism of action of piperlongumine analogs. Proc Natl Acad Sci U S A. 2012; 109(38):15115-15120.

19. Han JG, Gupta SC, Prasad S and Aggarwal BB. Piperlongumine chemosensitizes tumor cells through interaction with cysteine 179 of IkappaBalpha kinase, leading to suppression of NF-kappaB-regulated gene products. Mol Cancer Ther. 2014; 13(10):2422-2435.

20. Chaudhari N, Talwar P, Parimisetty A, Lefebvre d'Hellencourt C and Ravanan P. A molecular web: endoplasmic reticulum stress, inflammation, and oxidative stress. Front Cell Neurosci. 2014; 8:213.

21. Darling NJ and Cook SJ. The role of MAPK signalling pathways in the response to endoplasmic reticulum stress. Biochim Biophys Acta. 2014; 1843(10):2150-2163.

22. Leaver HA, Rizzo MT and Whittle IR. Glioma cell death: cell-cell interactions and signalling networks. Mol Neurobiol. 2010; 42(1):89-96.

23. Heath-Engel HM, Chang NC and Shore GC. The endoplasmic reticulum in apoptosis and autophagy: role of the BCL-2 protein family. Oncogene. 2008; 27(50):64196433.

24. Luo B and Lee AS. The critical roles of endoplasmic reticulum chaperones and unfolded protein response in tumorigenesis and anticancer therapies. Oncogene. 2013; 32(7):805-818.

25. Shuda M, Kondoh N, Imazeki N, Tanaka K, Okada T, Mori K, Hada A, Arai M, Wakatsuki T, Matsubara O, Yamamoto N and Yamamoto M. Activation of the ATF6, XBP1 and grp78 genes in human hepatocellular carcinoma: a possible involvement of the ER stress pathway in hepatocarcinogenesis. J Hepatol. 2003; 38(5):605-614.

26. Wang HC, Huang W, Lai MD and Su IJ. Hepatitis B virus pre-S mutants, endoplasmic reticulum stress and hepatocarcinogenesis. Cancer Sci. 2006; 97(8):683-688.

27. Yadav RK, Chae SW, Kim HR and Chae HJ. Endoplasmic reticulum stress and cancer. J Cancer Prev. 2014; 19(2):7588.

28. Gorlach A, Klappa P and Kietzmann T. The endoplasmic reticulum: folding, calcium homeostasis, signaling, and redox control. Antioxid Redox Signal. 2006; 8(9-10):13911418.

29. Kubota K, Niinuma Y, Kaneko M, Okuma Y, Sugai M, Omura T, Uesugi M, Uehara T, Hosoi T and Nomura Y. Suppressive effects of 4-phenylbutyrate on the aggregation of Pael receptors and endoplasmic reticulum stress. J Neurochem. 2006; 97(5):1259-1268. 
30. Marwarha G, Dasari B and Ghribi O. Endoplasmic reticulum stress-induced CHOP activation mediates the downregulation of leptin in human neuroblastoma SH-SY5Y cells treated with the oxysterol 27-hydroxycholesterol. Cell Signal. 2012; 24(2):484-492.

31. Brenner C, Galluzzi L, Kepp O and Kroemer G. Decoding cell death signals in liver inflammation. J Hepatol. 2013; 59(3):583-594.

32. Cruickshanks N, Tang Y, Booth L, Hamed H, Grant S and Dent P. Lapatinib and obatoclax kill breast cancer cells through reactive oxygen species-dependent endoplasmic reticulum stress. Mol Pharmacol. 2012; 82(6):1217-1229.

33. Li Y, Wu H, Jia M, Cui F, Lin J, Yang X, Wang Y, Dai $\mathrm{L}$ and Hou Z. Therapeutic effect of folate-targeted and PEGylated phytosomes loaded with a mitomycin C-soybean phosphatidyhlcholine complex. Mol Pharm. 2014; 11(9):3017-3026.

34. Liu SL, Shi DY, Shen ZH and Wu YD. Effects of glutamine on tumor growth and apoptosis of hepatoma cells. Acta Pharmacol Sin. 2000; 21(7):668-672.

35. Wang X, Sun K, Tan Y, Wu S and Zhang J. Efficacy and safety of selenium nanoparticles administered intraperitoneally for the prevention of growth of cancer cells in the peritoneal cavity. Free Radic Biol Med. 2014; 72:1-10.

36. Gong LH, Chen XX, Wang H, Jiang QW, Pan SS, Qiu JG, Mei XL, Xue YQ, Qin WM, Zheng FY, Shi Z and Yan XJ. Piperlongumine induces apoptosis and synergizes with cisplatin or paclitaxel in human ovarian cancer cells. Oxid Med Cell Longev. 2014; 2014:906804.

37. Kim TH, Song J, Kim SH, Parikh AK, Mo X, Palanichamy K, Kaur B, Yu J, Yoon SO, Nakano I and Kwon CH. Piperlongumine treatment inactivates peroxiredoxin 4, exacerbates endoplasmic reticulum stress, and preferentially kills high-grade glioma cells. Neuro Oncol. 2014; 16(10):1354-1364.

38. Roh JL, Kim EH, Park JY, Kim JW, Kwon M and Lee BH. Piperlongumine selectively kills cancer cells and increases cisplatin antitumor activity in head and neck cancer. Oncotarget. 2014; 5(19):9227-9238.

39. Wang Y, Wang JW, Xiao X, Shan Y, Xue B, Jiang G, He Q, Chen J, Xu HG, Zhao RX, Werle KD, Cui R, Liang J, Li YL and Xu ZX. Piperlongumine induces autophagy by targeting p38 signaling. Cell Death Dis. 2013; 4:e824.

40. Wang WQ, Liu L, Xu HX, Sun HC, Wu CT, Zhu XD, Zhang W, Xu J, Liu C, Long J, Ni QX, Tang ZY and Yu XJ. The combination of HTATIP2 expression and microvessel density predicts converse survival of hepatocellular carcinoma with or without sorafenib. Oncotarget. 2014; 5(11):3895-3906.

41. Soria LR, Marrone J, Calamita G and Marinelli RA. Ammonia detoxification via ureagenesis in rat hepatocytes involves mitochondrial aquaporin-8 channels. Hepatology. 2013; 57(5):2061-2071.
42. Ye SQ, Zhou XY, Lai XJ, Zheng L and Chen XQ. Silencing neuroglobin enhances neuronal vulnerability to oxidative injury by down-regulating 14-3-3gamma. Acta Pharmacol Sin. 2009; 30(7):913-918.

43. Zhang J, Lan SJ, Liu QR, Liu JM and Chen XQ. Neuroglobin, a novel intracellular hexa-coordinated globin, functions as a tumor suppressor in hepatocellular carcinoma via Raf/MAPK/Erk. Mol Pharmacol. 2013; 83(5):11091119.

44. Hu L, Duan YT, Li JF, Su LP, Yan M, Zhu ZG, Liu BY and Yang QM. Biglycan enhances gastric cancer invasion by activating FAK signaling pathway. Oncotarget. 2014; 5(7):1885-1896.

45. Lai XJ, Ye SQ, Zheng L, Li L, Liu QR, Yu SB, Pang Y, Jin S, Li Q, Yu AC, Chen XQ. Selective 14-3-3 $\gamma$ induction quenches p- $\beta$-catenin Ser37/Bax-enhanced cell death in cerebral cortical neurons during ischemia. Cell Death Dis. 2014; 5:e1184.

46. Towhid ST, Tolios A, Munzer P, Schmidt EM, Borst O, Gawaz M, Stegmann E and Lang F. Stimulation of platelet apoptosis by balhimycin. Biochem Biophys Res Commun. 2013; 435(2):323-326.

47. Pang LP, Huang W, Sun Q, Guo W, Li RT and Cui JR. SLXM-2, a derivative of cyclophosphamide: mechanism of growth inhibition on hepatocarcinoma 22 cells. Anticancer Drugs. 2008; 19(2):167-174. 